Hans-Jörg Schmid*

\title{
Why Cognitive Linguistics must embrace the social and pragmatic dimensions of language and how it could do so more seriously
}

DOI 10.1515/cog-2016-0048

Received May 3, 2016; revised August 2, 2016; accepted August 18, 2016

Abstract: I will argue that the cognitive-linguistic enterprise should step up its efforts to embrace the social and pragmatic dimensions of language. This claim will be derived from a survey of the premises and promise of the cognitivelinguistic approach to the study of language and be defended in more detail on logical and empirical grounds. Key elements of a usage-based emergentist sociocognitive approach known as Entrenchment-and-Conventionalization Model (Schmid 2014, 2015) will be presented in order to demonstrate how social and pragmatic aspects can be integrated and operationalized in a cognitive-linguistic framework.

Keywords: social turn in Cognitive Linguistics, pragmatics and Cognitive Linguistics, entrenchment-and-conventionalization model, implications of the usage-based approach

\section{Introduction: Premises, promise, and predicament of the cognitive-linguistic enterprise}

In my view, three main premises motivate the cognitive-linguistic enterprise: the cognitivist, the usage-based, and the emergentist premise. The cognitivist premise is that language interacts with other domains of cognition - notably categorization, memory, attention, perception, and reasoning - and follows the same cognitive principles as these (Ungerer and Schmid 2006: 343-346 et passim). The usage-based premise is that grammatical structure derives from experience in concrete usage events (Langacker 1988), and the emergentist that

*Corresponding author: Hans-Jörg Schmid, English and American Studies, LMU Munich, Germany, E-mail: Hans-Joerg.Schmid@anglistik.uni-muenchen.de 
shared linguistic knowledge is continuously reorganized by a variety of different mechanisms under the influence of language use (MacWhinney and O’Grady 2015).

The main promise of the cognitive-linguistic enterprise derives from these premises: cognitive linguists feel able to produce adequate and psychologically plausible explanations of cross-linguistically valid structural properties of language and of individual language-specific constructions.

Combining the premises and promise, the main assumptions behind Cognitive Linguistics can be summarized by formulating the explanandum (a) and the explanantia (b) to (e):

(a) The way language works and is structured can be modeled as deriving from

(b) general cognitive principles,

(c) experience in usage events,

(d) processes that are responsible for the way in which experience is transformed into knowledge,

(e) and the interaction between them.

So far, cognitive-linguistic research has made much more progress on explanans (b) than on (c), (d), and (e). We have been highly successful in detailing the ways in which linguistic structures can be explained and even assumed to be motivated by fundamental cognitive principles. In contrast, we seem to know much less about how these general cognitive principles interact (see explanans [e] above) with the online processing of linguistic experience in usage events (c), and with the diverse processes that are involved in transferring usage into grammar (d). A key insight regarding $(d)$ is of course that repetition contributes to the learning, routinization, and thus entrenchment of constructions (Bybee 2006; Langacker 2008: 16; Divjak and Caldwell-Harris 2015). This insight has certainly been a major step forward towards a better understanding of how grammar emerges from usage and has spawned an impressive body of corpus-based investigations of lexical and grammatical phenomena (see, e. g., Glynn and Fischer 2010).

However, the quantitative turn in Cognitive Linguistics brought about by this insight has also contributed to aggravating the predicament into which Cognitive Linguistics had already maneuvered itself by taking the usage-based premise on board. If we are serious about this premise, explanantia (c), (d) and (e) rise dramatically in importance and put a considerable extra burden on the promise of cognitive-linguistic theories. The reason is that they widen the range of the predictors of grammatical structure from cognitive to numerous other factors and mechanisms that can possibly contribute to the emergence of grammar from usage. As a result, Cognitive Linguistics has to venture far beyond 
the terrain allocated by its traditional mission. The most pressing of these questions pertain to the social, pragmatic, and sociopragmatic aspects of language that co-determine the way in which grammar emerges from usage and their interaction with cognitive processes:

- What are the effects of social structures and networks on linguistic experience in usage events and on the cognitive processes that mediate between usage and knowledge?

- What is the precise nature of the way in which the cognitive processes respond to the numerous pragmatic and sociopragmatic facets of usage events such as the communicative intentions of speakers, the social characteristics of the participants, and the social relations between them?

- What is the precise nature of these mediating processes, both cognitive and social ones?

To be sure, the mere fact that these questions are important has been taken for granted by many cognitive linguists all along (see, e. g., Langacker 2016). Some researchers in the field have actually been emphasizing the need for a social turn in Cognitive Linguistics for some time, most forcefully perhaps Harder (2010), but also, among others, Kristiansen and Dirven (2008), Croft (2009), and Geeraerts (2016; see Geeraerts and Kristiansen 2015 for a survey). Nevertheless, I believe it remains fair to say that the precise role played by social and especially pragmatic and sociopragmatic aspects in the transformation of usage into shared linguistic knowledge is not only still underestimated, but also not adequately integrated into cognitive-linguistic models of language. It is one thing to acknowledge in principle that pragmatic and sociolinguistic insights are important, but it is a challenge of quite a different order to come up with a unified model that incorporates them as integral parts of the predictive machinery. Therefore I would like to devote the present piece to justifying why Cognitive Linguistics should embrace the social, pragmatic, and sociopragmatic dimensions of language more seriously (Section 2), and to sketching a way in which this could be done (Section 3).

\section{Why should Cognitive Linguistics embrace the pragmatic and social dimension of language?}

\subsection{The logical why}

A closer scrutiny of the nature of linguistic experience provides the best start for running through the logical argument. Linguistic experience is collected in 
usage, and usage takes place in actual usage events. These in turn take place in social encounters between interactants who do many things in addition to using linguistic constructions: they try to make their communicative intentions mutually manifest, perform linguistic and non-linguistic acts (Austin 1962), and pursue extra-linguistic goals. In addition to these more narrowly "pragmatic" acts, they perform "sociopragmatic acts": they act out social roles and negotiate interpersonal relations on the basis of numerous social features of the usage event that they cannot help taking in: what is the person I am talking to like; what is the social relation between us; which identity am I going to assume here in view of this; what is the nature of the speech event; what are the norms and conventions of the speech event? If it is assumed that grammar derives from usage, and if we follow Halliday (1994) and others in further assuming that the interpersonal function of communication is at least as important as the ideational one for conveying and understanding meanings, then all these pragmatic and sociopragmatic facets of usage must clearly be factored into the model itself rather than being outsourced to other disciplines.

This is also mandatory because pragmatic and sociopragmatic, as well as genuinely social factors are in fact logically prior to cognitive factors. The input that the cognitive system gets and can work with is not only modulated by pragmatic and social exigencies, but actually afforded by the communicative intentions causing someone to use language in the first place, and motivated by the social activities, networks, and environments of language users. Whether speakers come across a certain word or construction, and how often and in which contexts they do so is ultimately determined by these communicative intentions, social environments and social processes.

It must thus be assumed on simple logical grounds that grammatical knowledge is not only distilled from ideational and structural properties of usage events, but also from the interpersonal, social and pragmatics ones (see Geeraerts 2016, for a more extensive theoretical discussion of this claim). What is more, these different properties of usage events are intertwined to such an extent that they can and must not be separated in such a way that only some of them are included inside the model. The next section will offer some empirical observations supporting this claim.

\subsection{Empirical whys}

First, consider one of the most fundamental insights of variationist sociolinguistics: speakers' linguistic preferences and habits co-vary with memberships in social groups (Tagliamonte 2006: 5-7). How could this fact be explained from a 
usage-based cognitive-linguistic perspective? Presumably, we would assume that the members of a social group or community of practice form linguistic routines and acquire linguistic knowledge by being exposed to the output of other members of the same social group. However, such group-specific entrenchment effects are only possible if we also assume that speakers store a tacit association linking the formal and semantic properties of constructions with knowledge about the groups of speakers who typically use these constructions. Both the structural and the interpersonal aspects must be part of what is distilled from usage into grammar.

Second, speakers do not only vary with regard to their own linguistic preferences, but they also have tacit or even explicit knowledge about the social values and meanings of the linguistic choices of others (Harder 2010). Knowledge of the stylistic meanings of constructions and their distribution across registers and genres arguably has the same roots: it derives from stored associations between formal and semantic properties of constructions, on the one hand, and situational, social and cultural contexts in which these constructions are typically used, on the other. In short, it is gleaned from rich experience in a myriad of usage events which are all marked for their social characteristics.

Finally, the effects of the processing of pragmatic, sociopragmatic, and social aspects of usage events can be observed in numerous mechanisms of language change such as grammaticalization, lexicalization, and especially semantic change by context-induced (re-)interpretation (Heine et al. 1991: Ch. 3) or invited inference (Traugott and Dasher 2004: 34-41). Details and illustrations of this will be given in Section 3.3 below.

In short, observations from the fields of variationist and interactionist sociolinguistics, from stylistics and discourse analysis, from semantics, and from language change support the logical argument that pragmatic, sociopragmatic, and social aspects of linguistic usage are inextricably intertwined with structural aspects in influencing the emergence of grammar from usage.

\section{How could Cognitive Linguistics embrace the pragmatic and social dimension of language?}

Up to this point I have argued that Cognitive Linguistics must spell out, rather than just acknowledge, the social and pragmatic dimension of language and integrate them within models of language use and linguistic knowledge. To the best of my knowledge, approaches that do justice to this insight have not been 
proposed so far. Geeraerts (2016) makes a powerful plea for integrating a sociosemiotic perspective into Cognitive Linguistics. However, as far as the pragmatic dimension is concerned, he mainly emphasizes that the socially shared linguistic system transcends the subjective communicative intentions of individuals from which it emerges. How this emergent process is to be modelled is not his main interest. Zlatev (2016) stresses the importance of intentionality and signitive intentions, but uses these terms in a phenomenological and semiotic rather than a pragma(linguis)tic sense.

I have tried to fill this gap by developing the so-called Entrenchment-and Conventionalization Model (see Schmid 2014, 2015; Schmid and Mantlik 2015), which is designed to integrate social, sociopragmatic, and pragmatic aspects into a cognitive-linguistic framework. This model owes massively to a large number of sources of inspiration ranging from "traditional" Cognitive Linguistics and usage-based approaches to the study of language structure, language change, and language acquisition to neurolinguistics, sociolinguistics, and pragmatics (see Schmid 2015: 5, for references). In view of the limited scope and specific aims of the present paper, I will only give a rough sketch of the main components of this model and then focus on the role played by social and (socio-)pragmatic aspects in it.

\subsection{The EC-Model in broad brush strokes}

The EC-Model consists of the four components presented in Figure 1: (1) usage and the activities it consists of; (2) a set of cognitive processes subsumed under the term entrenchment; (3) a set of social processes subsumed under the term conventionalization; and (4) a set of forces acting on usage, entrenchment, and conventionalization, as well as on the interaction between them. The central prediction of the model is that grammar is continuously re-organized by the interaction of entrenchment and conventionalization processes. These are triggered and sustained by the different activities involved in usage under the influence of cognitive, pragmatic, emotive-affective, and social forces. Entrenchment and conventionalization differ in terms of the nature of the processes involved and are therefore to be treated as separate systems which only interact via usage, as is indicated by the overlapping ellipses in Figure 1 (see Schmid 2015: 10-11 for a justification of this claim).

Entrenchment is defined in this model as the on-going reorganization of the associative network representing individual linguistic knowledge by means of the routinization of patterns of associations and their (re-)schematization. The term conventionalization subsumes social processes that are involved in the 
continuous mutual coordination and matching of linguistic knowledge and practices. The social processes that are considered necessary for an adequate account of empirical findings are innovation, co-adaptation (or accommodation), diffusion, and (implicit and explicit) normation. Prominent forces that have been identified so far include:

- cognitive forces: similarity, contiguity, salience, categorization, gestalt processing;

- $\quad$ pragmatic forces: settings, participants, event types, intentions, goals;

- emotive-affective forces: egocentrism, emotion, need for admiration, fun, empathy;

- social forces: social networks, identity and group-membership allocation, solidarity, peer-group pressure, prestige.

With this rough sketch of the overall model in mind, we can now turn to a closer look at how social, pragmatic, and sociopragmatic aspects are represented in the model and how they can be operationalized.

\subsection{How social aspects are implemented in the EC-Model}

Social aspects are integrated in the EC-Model in two ways: in the form of the conventionalization processes rendered on the right-hand side of Figure 1, and in the form of social forces. Social aspects are thus modelled in a dynamic fashion, i. e., as processes and forces. Traditional sociolinguistic variables such as region, gender, or age are treated as processes of group-membership allocation which act as pragmatic and social forces mediated by pragmatic associations (see below). Methodologically speaking, the conventionalization processes of innovation, co-adaptation, diffusion, and normation play the role of dependent variables, whose outcomes can be measured in different ways (again, see below for more details). In contrast, social forces like groupmembership allocation, social network structure and density, peer-group pressure, and prestige are independent variables alongside other co-predictors including not only the other types of forces but also the cognitive entrenchment processes. In what follows, some more concrete suggestions as to how linguists can "use the E\&C model in their daily descriptive/analytical practice", as Dagmar Divjak put it in her review of an earlier version of this paper, will be given.

The process of innovation, which makes up the starting-point of the conventionalization process of new utterance types, lends itself to an initial illustration of the way in which the dynamics of social aspects are 


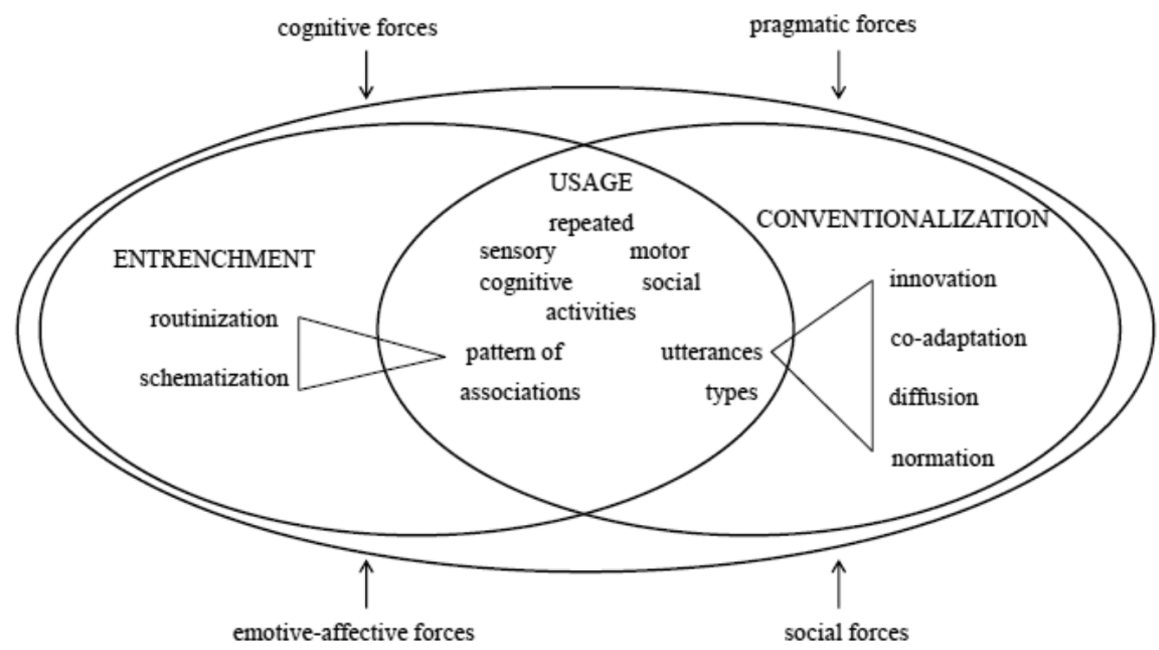

Figure 1: General outline of the EC-Model (taken from Schmid 2015: 7).

operationalized in the EC-Model. Innovation can roughly be defined as a process whose observable outcome is an utterance which is not licensed by a conventionalized utterance type. This product of an act of innovation is brought to life in the cognitive system by new associations which are based on existing association patterns (unless an utterance or word is created ex nihilo, which is very unusual). The process of innovation itself is triggered and supported by many factors which play the role of independent variables in empirical studies: by cognitive forces such as similarity (metaphor), contiguity (metonymy), analogy (based on single words or productive patterns), and other forms of recategorization (e.g., taxonomic changes); by social forces (e.g., peer-group pressure, prestige); by pragmatic forces (e. g., types of settings and participants); and by emotive-affective forces (fun, need for admiration). Importantly, what renders an innovation new and original is its difference to collectively conventionalized rather than to individually entrenched utterance types. What is new to one speaker may be perfectly conventional to another and vice versa. Innovation can thus only be explained by a model that keeps track not only of the current state of the associative network of the individual speakers, but also of the current state regarding the conventionality of an utterance type in the speech community. Since what is new ultimately depends on what is conventional, and not on what is entrenched, innovation is treated as a social process.

In the case of innovation, the observable datum is the actual utterance which is assessed as new against the backdrop of conventionalized utterance 
types. Evidence for co-adaptation processes is available in the form of repetitions of utterances or utterance types within the limits of one usage situation (Schmid 2015: 17-18). Evidence of this type can be collected in experimental studies (e. g., Fine et al. 2013) or by means of qualitative conversationbased methods such as discourse analysis or conversation analysis which have so far not been in the focus of attention of cognitive linguists. Valuable examples of studies of this type come from the tradition of discourse metaphor (e.g., Cameron and Deignan 2006) and from the emergentist tradition in conversation analysis (e.g., Auer and Pfänder 2011) which, inspired by the work of Paul Hopper (1987), looks into the sedimentation of conversational patterns in the linguistic system.

Diffusion and implicit normation (i.e., normation by usualization rather than by codification), the third and fourth social processes, take us closer to the quantitative, corpus-based studies which have come to dominate empirical approaches to Cognitive Linguistics over the past years (e. g., Glynn and Fischer 2010). Frequency of occurrence, the key dependent variable in most of these studies, first and foremost measures degrees of diffusion and usualization in speech communities or the parts thereof that are specified by the selection of corpora. From a cognitive-linguistic perspective, it is of course tempting to argue that increasing diffusion simply corresponds to more distributed entrenchment, i. e., to an increase in the number of members of a community who have a representation. This would render the process of diffusion redundant, because its job would be done by entrenchment processes. The very vagueness of the phrase "have a representation", however, already indicates the pitfall involved in this temptation: the same conventionalized utterance types can be entrenched in distinctly different ways in the minds of different speakers. Conventionality essentially means that speakers tacitly and mutually agree on how to solve communicative tasks given a range of equally arbitrary options (Lewis 1969; Croft 2000). Since this agreement relates to ways of putting things, conventionalization operates over utterance types, i. e., linguistic surface phenomena. Entrenchment, on the other hand, operates over patterns of associations, i. e., mental phenomena, which can differ substantially from speaker to speaker. The same utterance type can be represented in very different ways in terms of such dimensions as size and schematicity. Therefore, increasing diffusion in a speech community must not be reduced to more distributed entrenchment. By the same token, the existence of constructions, if defined as entrenched and conventionalized form-meaning/function pairings, should not be postulated rashly, since one conventionalized utterance type can be entrenched in different ways and to different degrees in the minds of different speakers. This is demonstrated for conventional German utterance types used for spatial descriptions of the type 
vorne rechts ("front right") vs. in der vorderen rechten Ecke ("in the front right corner") in eye-tracking studies by Günther (2016). Chang (2016) shows the same from a neurolinguistic perspective for various utterance types in Mandarin using the MMN component of ERPs.

\subsection{How pragmatic and sociopragmatic aspects are integrated in the EC-Model}

The main aim of integrating pragmatic and sociopragmatic aspects is to model how context-dependent phenomena eventually sediment into entrenched routines and conventionalized utterance types. This is taken care of by three components of the EC-Model: pragmatic and sociopragmatic aspects are registered during sensory, cognitive, and neuronal activities, modulated by pragmatic forces, and mediated to entrenchment processes by pragmatic associations.

First, sensory activities are responsible for the perception of situational characteristics of usage events, including information about settings and social characteristics of participants. The cognitive and neuronal activities involved in usage make a similarly fundamental contribution to explaining higher-level pragmatic effects such as pragmatic enrichment, context-sensitive disambiguation, and the working out of inferences of various types, including indirect speech acts (Searle 1975) and conversational implicatures (Grice 1975) (see below for more details and methodological implications).

Second, the effects of these activities on the entrenchment processes of association, routinization, and schematization are modulated by pragmatic forces. The extent to which individual processing events contribute to the routinization and schematization of association patterns depends on such pragmatic forces as our judgment of the kind of situation we find ourselves in ("setting"), the kind of interlocutors we are talking and listening to ("participants"), as well as their and our own communicative intentions and goals.

Third, the link between the sensory, cognitive, and neuronal activities and entrenchment processes is established by means of pragmatic associations. These connect sensory input garnered from the situation with the linguistic knowledge "stored" in the associative network. By linking usage and entrenchment, pragmatic associations play a key role in predicting the effects observed in Section 2.2. Repeated pragmatic associations between what is said in a given situation type and what is intended and achieved result in associative routines representing illocutionary acts, both direct and indirect (Searle 1975). The famous "illocutionary force indicating devices" (Searle 1969) such as sentence 
mood and intonation are thus explained in terms of routinized pragmatic associations between formal properties of utterance types and communicative intentions. The pathway towards such routinized pragmatic associations can be observed in highly conventionalized indirect speech acts such as could you pass me the salt or do you mind if I smoke. The result of this process is contextinduced language change (see Section 2.2), in which existing elements and routines acquire new meanings and functions that can ultimately be activated outside the corresponding contexts. The new meanings are subserved by new or newly enriched symbolic associations rather than computed by means of inferences drawn with the help of pragmatic associations.

The same rationale explains the other cases discussed in Section 2.2. Here, sociopragmatic rather than genuinely pragmatic aspects come to the fore. Sociolinguistic preferences and sociolinguistic awareness as well as style and register awareness come about by the entrenchment of pragmatic associations connecting sociopragmatic experience in concrete usage events with the formal and semantic properties of the linguistic elements used in them.

While all these processes as such can be described in the form of general pragmatic mechanisms, the way they apply in specific contexts remains largely unpredictable. This is one of the main reasons why they have not played a prominent role in empirical studies so far and why the field of cognitive pragmatics has not yet managed to exhaust its full potential (Bara 2010; Schmid 2012). The operationalization of pragmatic and sociopragmatic aspects thus poses a particularly daunting challenge both for the EC-Model and for Cognitive Linguistics in general.

To tackle the easier part first, some of the standard pragmatic and sociopragmatic variables and forces are by no means new to Cognitive Linguistics, but have been integrated as independent variables in corpusbased and experimental studies all along: pragmatic variables such as medium (written, spoken, signed, computer-mediated), mode (monologue, dialogue, mass communication etc.), setting (private, public, institutional etc.), and social characteristics of participants are often included as co-predictors in multivariate corpus-based studies and should be controlled for in experimental studies. This also holds for more or less direct grammatical reflections of pragmatic aspects, for example sentence mood (declarative, interrogative, imperative) as a rough indicator of types of illocutionary acts, as well as topicalization and focus constructions, theme-rheme distribution, and the position and weight (i.e., length) of constituents as markers of information structure.

The long-term effects of interpretative processes such as pragmatic enrichment and conversational implicature on entrenchment and conventionalization 
are much harder to operationalize, mainly because these processes are - by definition - context-dependent. The main handle for grasping them methodologically lies in the usage-based premise: context-dependent inferential processes are only able to have an effect on entrenchment and conventionalization if they are repeated. Similar utterances must give rise to similar pragmatic associations in similar contextual and cotextual environments. The key to spotting the effects of repeated pragmatic processes thus lies in the observation of repeated usage patterns that are associated with specific communicative intentions and/or nonliteral meanings in specifiable contexts and co-texts. For corpus studies, this means that attestations of lexico-grammatic patterns must be subjected to close manual analysis of cotexts, contexts, meanings, and communicative functions (cf. Schmid 2013, 2014). In diachronic corpus investigations, changes with regard to the entrenchment and conventionalization of pragmatic associations can be indicated by salient non-linear developments of frequency of usage, and/or by noticeable inter-individual variation regarding the communicative functions of lexico-grammatical patterns (Schmid and Mantlik 2015).

\section{Conclusion and outlook}

Cognitive linguists have produced a massive body of work contributing substantially to our understanding of how language works, and so have our colleagues in different branches of pragmatics and sociolinguistics. Why, the reader may be inclined to ask, should we give up this successful division of labor and begin to integrate pragmatics and sociolinguistics inside cognitivelinguistic models rather than keeping them outside as esteemed neighbors willing to give us a helping hand when necessary? The answer given in this paper essentially boils down to the well-known truism that everything hangs together with everything. Grammar, both individual and collective, is not only shaped by cognitive principles and processes, but also by the pragmatic, interpersonal, and social functions of language, and by pragmatic and social processes and forces. What is more, all these processes and forces constantly interact to such an extent that it is very difficult or even impossible to disentangle their effects. This means they must all be the integrated in the model. In this paper, I have tried to make a case for this insight and to offer a glimpse of how the Entrenchment-and-Conventionalization Model attempts to do justice to it.

As regards the future development of Cognitive Linguistics, I personally do not expect that Cognitive Linguistics will eventually dissolve into a hotchpotch 
of sociopragmacognitive usage-based emergentism. For one thing, despite ongoing attempts in many sciences to keep sight of the bigger picture, the trend towards increasing specialization is unlikely to be reversed, because the more detailed our questions become the more local in-depth expertise will be required for answering them. And for another, even if the EC-Model and similar integrative approaches like the theory of complex adaptive systems (The Five Graces Group 2009) may prove to hold some appeal, it is obvious that their main theoretical strength, i.e., their wide scope and considerable explanatory potential, is also their main methodological weakness: the whole models as such are very difficult, if not impossible, to test. ${ }^{1}$ What such models can do, however, is spawn more concrete falsifiable hypotheses that can be tested in ways suggested in the present paper and exemplified by studies like Chang (2016), Günther (2016), and Schmid and Mantlik (2015). My prediction therefore is that even if the number of cognitive linguists who strive to integrate pragmatic, sociopragmatic, and social aspects might be going to increase over the next years, it is unlikely that this will do much harm to the cognitivelinguistic enterprise as such.

Acknowledgements: I would like to thank Dagmar Divjak, the supervising guest editor in charge of this contribution, and three anonymous reviewers for their valuable comments on an earlier version of the paper. In addition, I want to express my gratitude to the large number of outstanding scholars whose work has been a great source of inspiration for the ideas presented here, most notably Joan Bybee, Bill Croft, Penelope Eckert, Charles Fillmore, Dirk Geeraerts, H.P. Grice, William Labov, Ron Langacker, Brian MacWhinney, John Searle, John Sinclair, Len Talmy, Michael Tomasello, and Alison Wray.

\section{References}

Auer, Peter \& Stefan Pfänder (eds.). 2011. Constructions: Emerging and emergent. Berlin: De Gruyter.

Austin, John L. 1962. How to do things with words. Oxford: Clarendon.

1 I strongly believe that no model of language that does justice to its structural, social, and pragmatic complexities is testable, let alone falsifiable. In general, it is quite striking that most linguists tend to invoke the requirement of falsifiability when judging the theories of other linguists (rather than their own). 
Bara, Bruno. 2010. Cognitive pragmatics. The mental processes of communication, trans. from Italian by John Douthwaite. Cambridge, MA: MIT Press.

Bybee, Joan. 2006. From usage to grammar: The mind's response to repetition. Language 82(4). 711-732.

Cameron, Lynne \& Alice Deignan. 2006. The emergence of metaphor in discourse. Applied Linguistics 27(4). 671-690.

Chang, Paul Yu-Chun. 2016. The entrenchment and conventionalization of linguistic knowledge: A neurolinguistic perspective. Munich: LMU dissertation.

Croft, William. 2000. Explaining language change: an evolutionary approach. Harlow \& New York: Longman.

Croft, William. 2009. Toward a social cognitive linguistics. In Vyvyan Evans \& Stephanie Pourcel (eds.), New directions in cognitive linguistics, 395-420. Amsterdam \& Philadelphia: John Benjamins.

Divjak, Dagmar \& Catherine L. Caldwell-Harris. 2015. Frequency and entrenchment. In Ewa Dąbrowska \& Dagmar Divjak (eds.), Handbook of cognitive linguistics, 53-75. Boston \& Berlin: De Gruyter Mouton.

Fine, Alex B., T. Florian Jaeger, Thomas A. Farmer \& Ting Qian. 2013. Rapid expectation adaptation during syntactic comprehension. PLOS ONE 8(10). e77661. doi: 10.1371/journal. pone.0077661.

Geeraerts, Dirk. 2016. The sociosemiotic commitment. doi: 10.1515/cog-2016-0058.

Geeraerts, Dirk \& Gitte Kristiansen. 2015. Variationist linguistics. In Ewa Dąbrowska \& Dagmar Divjak (eds.), Handbook of cognitive linguistics, 366-389. Boston \& Berlin: de Gruyter Mouton.

Glynn, Dylan \& Kerstin Fischer (eds.). 2010. Quantitative methods in cognitive semantics: Corpus-driven approaches. Berlin: Walter de Gruyter.

Grice, H. Paul. 1975. Logic and conversation. In Peter Cole \& Jerry L. Morgan (eds.), Syntax and semantics, Vol. 3: Speech acts, 41-58. New York: Academic Press.

Günther, Franziska. 2016. Constructions in cognitive context. Why individuals matter in linguistic relativity research. Berlin \& Boston: Walter de Gruyter.

Halliday, Michael A.K. 1994. An introduction to functional grammar, 2nd edn. London: Edward Arnold.

Harder, Peter. 2010. Meaning in mind and society: A functional contribution to the social turn in cognitive linguistics. Berlin \& New York: De Gruyter Mouton.

Heine, Bernd, Ulrike Claudi \& Friedericke Hünnemeyer. 1991. Grammaticalization: A conceptual framework. Chicago, IL: University of Chicago Press.

Hopper, Paul. 1987. Emergent grammar. Berkeley Linguistics Society 13. 139-157.

Kristiansen, Gitte \& Rene Dirven (eds.). 2008. Cognitive sociolinguistics: Language variation, cultural models, social systems. Berlin: Mouton de Gruyter.

Langacker, Ronald W. 1988. A usage-based model. In Brygida Rudzka-Ostyn (ed.), Topics in cognitive linguistics, 127-161. Amsterdam \& Philadelphia: Benjamins.

Langacker, Ronald W. 2008. Cognitive grammar: A basic introduction. Oxford \& New York: Oxford University Press.

Langacker, Ronald W. 2016. Working towards a synthesis. doi: 10.1515/cog-2016-0004.

Lewis, David. 1969. Convention. A philosophical study, Oxford: John Wiley \& Sons.

MacWhinney, Brian \& William O'Grady (eds.). 2015. The handbook of language emergence. Oxford: Wiley Blackwell. 
Schmid, Hans-Jörg (ed.). 2012. Cognitive pragmatics. Handbooks of pragmatics - Vol. 4. Berlin: Mouton de Gruyter.

Schmid, Hans-Jörg. 2013. Is usage more than usage after all? The case of English not that. Linguistics 51(1). 75-116.

Schmid, Hans-Jörg. 2014. Lexico-grammatical patterns, pragmatic associations and discourse frequency. In Thomas Herbst, Hans-Jörg Schmid \& Susen Faulhaber (eds.), Constructions collocations patterns, 239-293. Berlin \& Boston: De Gruyter Mouton.

Schmid, Hans-Jörg. 2015. A blueprint of the cntrenchment-and-conventionalization model. Yearbook of the German Cognitive Linguistics Association 3. 1-27.

Schmid, Hans-Jörg \& Annette Mantlik. 2015. Entrenchment in historical corpora? Reconstructing dead authors' minds from their usage profiles. Anglia 133(4). 583-623.

Searle, John R. 1969. Speech acts. Cambridge: Cambridge University Press.

Searle, John R. 1975. Indirect speech acts. In Peter Cole \& Jerry L. Morgan (eds.), Syntax and semantics - Vol. 3: Speech acts, 59-82. New York: Academic Press.

Tagliamonte, Sally A. 2006. Analyzing sociolinguistic variation. Cambridge: Cambridge University Press.

The Five Graces Group [ = Clay Becker, Richard Blythe, Joan Bybee, Morten H. Christiansen, William Croft, Nick C. Ellis, John Holland, Jinyun Ke, Diane Larsen-Freeman, Tim Schoenemann]. 2009. Language is a complex adaptive system: Position paper. In Nick C. Ellis \& Diane Larsen-Freeman (eds.), Language as a complex adaptive system, 1-26. Chichester: Wiley-Blackwell.

Traugott, Elizabeth C. \& Richard B. Dasher. 2004. Regularity in semantic change. Cambridge: Cambridge University Press.

Ungerer, Friedrich \& Hans-Jörg Schmid. 2006. An introduction to cognitive linguistics, 2nd edn. London \& New York: Pearson Education.

Zlatev, Jordan. 2016. Turning back to experience in cognitive linguistics via phenomenology. doi: $10.1515 / \operatorname{cog}-2016-0057$. 